\title{
The Digital Transformation of Education
}

\author{
Ravi Kapur, Val Byfield, Fabio Del Frate, Mark Higgins, \\ and Sheila Jagannathan
}

\begin{abstract}
For society to benefit fully from its investment in Earth Observation, the data must be accessible and familiar to a global community of users who have the skills, knowledge and understanding to use the observations appropriately in their work. Future 'Environmental Data Scientists' will need to draw on multiple data and information sources, using data analysis, statistics and models to create knowledge that is communicated effectively to decision-makers in government, industry, and civil society. Networks, cloud computing and visualization will become increasingly important as citizen scientists, data journalists and politicians increasingly use Earth observation products to give their arguments and decisions scientific credibility.

The overarching aim of Earth Observation education must therefore be to support life-long learning, allowing users at all levels to remain up-to-date with EO technologies and communication mechanisms that are relevant to their individual needs. Current and emerging methodologies for interactive education (such as "MOOCs" and mobile learning), and hands-on engagement with real data (such as through citizen science projects) will be central to outreach, training and formal education in this field. To achieve this, it will be important to engage a wider community of experts from a range of disciplines, and to establish a comprehensive network of educators, technical experts, and content producers. It will also be important to encourage "crowd-sourcing" of new contributions, to help maintain scientific and educational quality. A case study from the World Bank's Open Learning Campus illustrates the opportunities to influence thinking much beyond the environmental data scientist community.
\end{abstract}

\author{
R. Kapur $(\bowtie)$ \\ Imperative Space, London, UK \\ e-mail: ravi.kapur@imperativespace.com \\ V. Byfield \\ National Oceanography Centre, Southampton, UK \\ F. Del Frate \\ University of Tor Vergata, Rome, Italy \\ M. Higgins \\ EUMETSAT, Darmstadt, Germany \\ S. Jagannathan \\ World Bank Group, Washington, DC, USA
}

(C) The Author(s) 2018

P.-P. Mathieu, C. Aubrecht (eds.), Earth Observation Open Science and Innovation,

ISSI Scientific Report Series 15, https://doi.org/10.1007/978-3-319-65633-5_2 
Environmental stewardship has "gone mainstream". In just a few short years, public understanding of the vulnerabilities of our environment has moved from marginal to a central part of policy, public discourse and education. The achievement of this tipping point has been so emphatic that there is now a growing and tangible demand, even a thirst, amongst the general population for greater knowledge about how the Earth system works and how to protect it.

EO has been at the heart of the creation of this societal imperative, from the cultural impact of the first Apollo images of the Earth, to the increasing familiarity of astronaut photography and high resolution video from LEO, distributed through social media, news outlets and mainstream media. But there remains a significant disconnect between this increased awareness of EO data, and a detailed understanding of its applications and what it can truly reveal.

To sustain this interest and increase the depth of public and professional understanding of the data, there is a need for new forms of education and training which can cut through a fast-moving and information-rich world. A new generation of decision-makers, social entrepreneurs, educators, media professionals and active citizens are looking to equip themselves quickly and efficiently with deployable, practical knowledge and skills, and the confidence to bring EO data into their work.

Simultaneously, the scientific research community, along with environmental and humanitarian organizations, is in need of a greater through-flow of skilled and knowledgeable data scientists and remote sensing experts. They require the tools to quickly share new ideas, techniques and practice, and provide a window onto emerging developments in EO across multiple disciplines.

Fortuitously, these needs have converged with key developments in a number of arenas which now make all of this possible. Advances and growth in online education, the "open educational resources" (OER) movement (Atkins et al. 2007), and interactive web technologies have coincided with the emergence of open EO data, easier access to high resolution imagery, and a thriving EO app development scene. This has made it possible to provide accessible but authoritative mass education and training and opportunities to work practically with EO data, to diverse audiences around the world.

There are challenges associated with configuring online learning in a way that accommodates a wide array of prior knowledge. Ensuring that the training provided is accessible enough for newcomers but also credible to those with some expertise requires a careful and detailed "learning design" process and clearly signposted pathways to further in-depth learning. But when this is done well, the outcome can be a powerful combination of professional development and academic learning for some learners, and an inspirational and awareness raising tool for new audiences.

A key initial step is to ensure that the learning design is linked to the desired learning outcomes. The process becomes complicated when the course modules target learners who have very different stocks of prior knowledge and different learning objectives, such as raising awareness, professional development or academic learning. A case study from the World Bank's Open Learning Campus (OLC) illustrating how these challenges could be met is included in this paper. 
The synergies between the nature of EO education and training, and the growth of interactive online learning create great opportunities for both arenas. The results can often go beyond intended learning, outcomes, with an often emotional and empowered response from those understanding for the first time what EO data can reveal, which in turn may have knock-on societal benefits.

This has been greatly exemplified in a series of EO "MOOCs" (massive open online courses) which have been instigated by ESA. The first two ESA MOOCs (focused on climate monitoring and sensing in the optical realm respectively), along with a course from EUMETSAT (on ocean monitoring) have had over 30,000 registered participants in just 2 years, and further courses are planned. These courses have focused principally on data applications, but have also provided rudimentary training on the basis and history of satellite EO technology and instrumentation, and have acted as a hub for various data access and visualization tools to enable even novice learners to experiment directly with real data.

ESA's first full-scale MOOC, on "Monitoring Climate from Space", was a 5-week course deployed initially on the FutureLearn platform, consisting of a total of 30 original videos, interactive tests and exercises, and $3-5 \mathrm{~h}$ of independent study each week. The course attracted 9000 registrants on its first "run", with a participation rate of over $54 \%$ and a course completion rate of $22 \%$, above average for large-scale MOOCs on FutureLearn. Over $80 \%$ of participants were classified as "active learners" (i.e. following through multiple steps of the course), and around $30 \%$ were classified as "social learners", actively involved in peer-learning and online comments. Additionally, the course achieved exceptional qualitative outcomes, with very high approval ratings for the format, quality and "layered" nature of the content, and very high levels of "emotional engagement" and stated intention to continue with further learning in the subject. Significant numbers of newcomers to the subject expressed a profound new appreciation of Earth science, the evidence for climate change and the detail of the data available through satellite observations. Others with existing knowledge of the policy and environmental contexts expressed a renewed intention to incorporate EO into their professional work and decision-making, and an interest in deepening their knowledge of the data and applications (Figs. 1 and 2) (ESA Monitoring Climate from Space MOOC 2015; FutureLearn 2015).

The mix of backgrounds and professions of the course participants was also revealing, ranging across EO and climate scientists, satellite engineers, climate
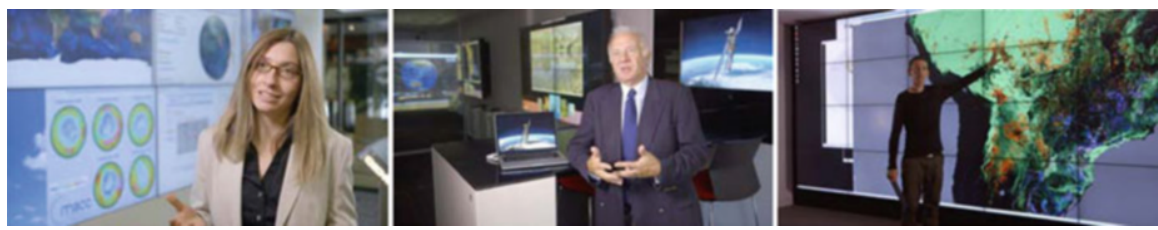

Fig. 1 Stills from ESA Monitoring Climate from Space MOOC videos. Source: Imperative Space/ESA 

This course has been fantastic, certainly the most interesting, informative
and enlightening Future Learn course I have taken to date - in fact I have
found the whole content of this course so interesting that I have just applied
to study for a distant-learning GIS MSc degree! It has been a most enjoyable
journey - am not sure how I am going to fill my time next week! Massive thanks to all the team!

My special thanks to all the course instructors, ESA and Future Learn. This course did not only sharpen my skills in EO, but has added value to my career life, prepared me for my next degree. The knowledge that I have acquired during this course has brought a new level of understanding when reading various remote sensing articles..

The course has inspired me to such an extent that I am interested to engage myself in an institutional course on Earth Observation and remote sensing. Due to my educational qualification, B.Sc.(Physics), I have enjoyed the course.

This has been a very wonderful experience for me considering the fact that I just joined one of the six activity centres of the National Space Research and Development Agency, Nigeria as a Research Fellow. A million thanks to all the seasoned instructors and tutors. I look forward to being part of another course like this from the ESA.

Fig. 2 Example end-of-course learner comments from ESA Monitoring Climate from Space MOOC. Source: Imperative Space/ESA

diplomats, policy-makers, senior decision-makers, school teachers, students (high school, undergraduate, postgraduate and home-educated), campaigners, media professionals, science communicators, retired individuals and casual learners. This demonstrated the potential of MOOCs and OER to address all levels of need in EO education and training, which can be broadly grouped as follows:

1. Students in higher education (including those on courses or in research in "adjacent" fields).

2. Professional development and knowledge transfer (for existing data scientists, and other professionals working with EO).

3. School-based education (especially high school, where links to the curriculum are essential-Early EO education can be seen as "capacity building" for EO skills, two generations hence).

4. Awareness-raising and orientation (for newcomers to the field, including decision and policy makers, professional communicators and educators, and the wider public).

All of these areas have a common set of challenges to which new forms of education and training are applicable, but they also have distinct problems which require specific considerations, as outlined below.

In general, EO data is inherently powerful and compelling once understood, but for many potential new audiences it feels inaccessible and highly technical. There are perceived barriers to entry which stem from the technical terminology used, the diversity of data types and the myriad of data portals. It is important to "personalise" the concepts of EO for new audiences and to make the content feel less "remote". "Emotional engagement" and the personal impact of EO imagery and data play an important part in establishing an "embedded" understanding of EO, and in creating a sense of responsibility for the issues the data reveal. In EO education, this level 
of engagement can be achieved through clear learning design and explanation, but also through high "production values" in the quality of apps, animation, video, infographics, data visualization and "story-telling".

For new and general audiences, OER-based approaches to EO education (especially those which are video-led such as MOOCs) show greatest added value when they serve to "demystify" the subject and increase the visibility of the data and its applications, (i.e. actually "showing" learners how EO technology and data applications work, what the data looks like, and how it can have impact, in science and "on the ground" through real-world case studies).

In the case of higher education, traditional modes of delivery are not well geared to the demands and pace of EO education and training, and radical changes online have already begun to occur which should be embraced by the EO arena. The basic model of higher education existing today was created in the eleventh century, operates on a nineteenth-century calendar and model, and yet is still expected to prepare students for life in the twenty-first century. Technology is now widely changing the game in higher education by leveraging the potential of "social learning". Rapid developments in information and communication technologies (ICT), and in particular the Internet (web 2.0), have enabled consumers of content to become producers of content, and share this content through social networking sites, blogs, wikis and virtual communities. These technology developments have enabled the emergence of a more participatory approach for open online distance education, especially in the form of MOOCs, and the use of more innovative learning materials (such as videos, audio recordings, interactive tests and collaborative exercises). A popular and early example of the MOOC was MIT's Open Course Ware initiative, which today provides open access to undergraduate and graduate-level materials and modules from more than 1700 courses. Other initiatives, such as the Open University, iTunesU and the Khan Academy, are also key precursors of Open Educational Resources (OER) (Mehaffy 2012; Diaz et al. 2013).

The term "MOOC" was first coined by Dave Cormier in 2008 for a course on "Connectivism and Connective Knowledge". The idea however took off in 2011 when Sebastian Thrun and Peter Norvig, at Stanford University, decided to offer the course "Introduction to Artificial Intelligence" free to anybody in the world. They sent out a single e-mail, and 160,000 people from 190 countries signed up. More than 23,000 students completed the course, and by the end of the course, only 30 of the original 200 Stanford students were still going to face-to-face classes. Out of the 23,000-plus course completers, 248 students had a perfect score in the course, and none of them were Stanford students (Fig. 3) (Mehaffy 2012).

MOOCs are widely regarded as being part of a new paradigm (and possibly revolution) in "democratization of a new type of education serving the needs of twenty-first century students", enabling higher education transition towards digital networked learning. The success of the MIT project led to the creation of Udacity in 2012, and inspired many universities to start their own OER and MOOC initiatives, such as EdX, Coursera, and FutureLearn, to deliver free educational material to millions of people across the world. While some await further evidence for the long term impact of MOOCs, it is apparent that the OER movement is well aligned with the learning expectations of the new generation of higher education students, and 


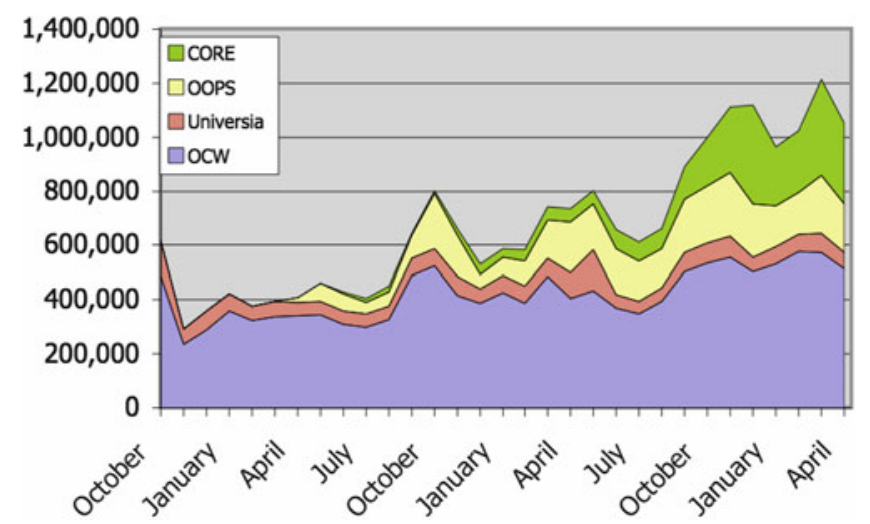

Fig. 3 Monthly visits to MIT OpenCourseWare site, October 2003 to April 2006. Figure above includes OCW translated sites: Universia (Spanish/Portuguese); Open Resources for Education (CORE); Opensource Opencourseware Prototype System (OOPS-Taiwan) (Smith \& Casserly 2006)

is particularly well attuned to fast-moving, visual and complex subjects such as EO (Mehaffy 2012).

The ESA MOOCs have in some respects built on the work of previous online EO education projects supported by ESA such as the Learn EO! initiative and the Bilko software. What is different about the MOOCs however is that rather than providing a set of resources tailored for particular target audiences, they are instead designed to offer a spectrum of depth-of-learning for wide ranging audiences. The conundrum for the learning designers has been in finding a way to create a broad offering, whilst responding to the increasing expectation of online learners for a personalized experience. In the ESA courses, a sense of personalization comes in two forms: firstly the "social learning" aspects (including online discussions with other learners and feedback from expert educators); and secondly the range of options available for self-directed learning beyond the core materials of the course.

Others have approached the challenge of personalization of MOOCs in alternative ways. For example, the World Bank Group, which has invested heavily in MOOCs and online learning to help support sustainable development goals, uses online courses as part of a "blended" education and capacity building approach. Their principal target audience is "mid-career" practitioners involved in development, and their aim has been to create a flexible, collaborative learning approach.

This has taken the form of the "Open Learning Campus" (OLC), which includes a combination of full-scale MOOCs, "bitesize" learning resources, short "e-courses" and some face-to-face training (both online and in centres). This has led to a shift in the capacity building training and education delivered by the World Bank online from $5 \%$ to $95 \%$ over 4 years.

The OLC has so far made available six MOOCs, 500 short courses and 5000 bitesize resources, and their own analysis has concluded that this has enabled 350,000 target learners to access structured education and training, equivalent to around 10,000 face to face training courses delivered in a conventional way. 
The flexible array of learning tools provided by the OLC now also includes resources tailored for on-the-move and "just-in-time" mobile learning. They are also pioneering the use of AI to further personalize the learning experience based on prior courses and other preferences.

Over the last 10 years, substantial evidence has started to emerge about the impact of online and video-led professional development training and knowledge transfer in a range of sectors. It has been shown to be particularly effective in sectors where there is a need to break down professional "silos" and enable a crossdisciplinary approach to innovation. This could be said to be very applicable to the training and professional development needs in EO. MOOCs and other forms of structured OER provide an ideal way to quickly unlock critical information and impart know-how for both professional and casual learners.

Professor Richard Elmore from the Harvard Graduate School has described learning as "the conversion of information into knowledge". In fast-innovating fields such as EO, professionals are often operating at the very limit of their knowledge, using the latest innovation they are aware of. To help them incorporate new knowledge into their work, they often need to be literally "shown" latest information and how innovations are being applied elsewhere (Elmore 2015a, b). In the EO arena, the emerging big data revolution will present a challenge for organizing the vast amounts of new data into accessible information, but it will also be a corresponding challenge for EO education to convert that information into tangible, understandable and applicable knowledge.

In the case of knowledge transfer and general awareness raising of EO in other arenas, much can also be learned from the use of OER and video-led training in other areas of science. For example, the UK research funding body EPSRC (Engineering and Physical Sciences Research Council) have, like other science bodies, used video extensively to showcase the capabilities and facilities of their grant recipients to industry, in order to promote and foster new research collaborations. For instance, in 2010/11 EPSRC funded a major UK university, the University of Sheffield, to showcase its large-scale and interdisciplinary research activities, expertise and infrastructure through a series of over 40 short documentary films, accompanied by other forms of text-based information. Watched in their entirety, the videos (presented in six thematic areas relating to major global challenges), represent a form of ad hoc, on-demand training course. In practice, the videos were viewed by their target audience over 150,000 times, were shown at numerous professional and public events and had additional public engagement impacts. The project overall is believed to have led to many significant investments and funded research partnerships, and has been emulated with follow-up video projects of this kind (Research at Sheffield 2010). MOOCs and similar video resources could greatly help to raise the visibility of EO data and applications in this way, amongst policymakers, senior business executives and funders, effectively training them as "casual" learners.

MOOCs and OER also have a role to play in bringing EO education into high school-based learning, but the approach to how these tools are used has to be modified to take into account the "time poverty" experienced by many teachers, 
and the need to align resources to the curriculum. School-based education is generally still fairly formalized, and ease of access, in-depth curriculum links and teacher guidance are essential requirements for ensuring take-up in schools. On the other hand, there is often a willingness to embrace technology and create skillsbased and personalized learning. EO provides inspirational and compelling learning opportunities in the science, geography and "citizenship" curricula. Educational research has also established that giving students in schools the opportunity to engage directly with real scientific data, (and even contribute to real scientific research), has an extremely positive effect on student engagement, familiarity with key subject matter, follow-on educational interests, and attainment levels. Engaging with real scientific data also helps students to orientate themselves geographically, and provides them with a better understanding of physical aspects of the world around them, such as a sense of scale and rates of change of natural processes. Much of the subject matter in traditional science curricula relates to phenomena which are either too large or too small to be observed directly, so creating a sense of scale and enabling visual understanding of scientific concepts is key to in-depth learning. EO data has the potential to play a significant role in this (Kapur et al. 2007; Facer 2007). At higher levels, the concept can evolve and be scaled up to the Fablab experience, as originally born at MIT's Center for Bits \& Atoms Fab Lab Program. In this case, as in the "Fabspace 2.0" project (2016) the main objective is to set up and operate at a university level a free access place and service where students, but also researchers and external people, can make use of a data platform and, under the open innovation umbrella, design and test their own geoinformation applications using EO images.

EO-related citizen science also offers substantial and wide-ranging opportunities in EO education, enabling teachers to explore EO data with their students in a structured manner, and embed it into curriculum delivery and formal teaching. Teachers and students generally relish the opportunity to engage directly with realworld data. It creates depth of learning and insights that are not possible otherwise, and maximises the prospect of students feeling they can make a contribution to science. And there are opportunities for EO education to emulate the successful open research collaborations taking place in other areas of science education. For example, in astronomy a "crowd-sourcing" approach has been established to enable student access to real science infrastructure, such as through the National Schools Observatory project in the UK, and the Faulkes Telescope initiative (Faulkes Telescope Project 2008; National Schools Observatory Project n.d.). Elsewhere, other projects use supercomputer simulation models, or enable school students to engage personally in research side by side with researchers, such as the LUCID project and other initiatives at the Langton Star Centre in the UK (LUCID Project/Langton Star Centre 2014). In lower age groups, EO education is well-placed to capitalize on emerging research into cloud-based education methodologies, such as the "SelfOrganised Learning Environments" (or "SOLEs") being pioneered by Professor Sugata Mitra (Dolan et al. 2013).

New variations on the MOOC concept are already emerging which could further widen the potential uses of these approaches in EO education and training. For 
example, the MOOC tools and format can be delivered to more limited numbers rather than being "massive" (so-called "OOCs"), or distributed to large but private audiences rather than being fully "open" ("MOCs"). Several universities have experimented with the concept of "XMOOCs", where tailored courses are created from a centralized pool of OER and video content, and disseminated through a range of pathways rather than a single platform. Such an approach could be highly applicable to EO education, where content needs to be drawn from multiple agencies and research groups and courses need to be regularly updated. Others are creating courses where content is only accessed "on-demand", with learners encouraged to "re-mix" or "mash-up" the content and share it as they need. What remains essential however, is the need for consistency and clarity of learning design, ensuring ease of access to the content, and supporting opportunities for collaborative, social learning (Diaz et al. 2013; Brown \& Adler 2012).

While MOOCs can offer a rich, open and flexible learning experience, they are in effect a new "instructional genre" (Mitchell et al. 2015), and we must use new metrics for assessing their impact and modify our expectations in evaluating success. To many learners using these new tools, "success metrics" and "completion" may not have the same meaning as in traditional education. In the case of EO especially, many learners will be happy to simply access the information they are most interested in, be exposed to new ideas and discover new applications, rather than seek formal accreditation or qualifications (Liyanagunawardena et al. 2014).

Techniques such as MOOCs also enable a two-way flow of insights, helping to inform trainers of what a particular group of learners knows and does not know about EO and the environment, and benefitting the scientific community through the fresh questions and challenges posed by learners. MOOCs include stimulus questions and discussions, and the participants are invited to discuss topics raised in the videos in whatever way they wish. For example, in the EUMETSAT Monitoring the Oceans from Space MOOC, many questions were asked about how the quality of the satellite data is assessed. The participants were using their own language to articulate questions of calibration and validation. These questions provide an indication of how the "story" of creating and managing data sets in science could be told in new ways. The participants seemed to have a real appreciation for the contribution of data validation to the scientific disciplines that rely on the data. As an important side benefit to the main aims of the course, the MOOC showed learners how this key part of the science works by teaching them about specific areas of the science itself.

MOOCs can also be effective in placing the learner at the heart of the science, enabling them to better appreciate the implications of EO data and applications for themselves and their communities. The ESA and EUMETSAT MOOCs have all been designed to highlight connections between the satellite observations, the resulting science and applications, and the impact and opportunities for the individual citizen. Providing tools for participants to create and share examples of their findings is an important element in the teaching process for these MOOCs. This mirrors the process for professionals involved in EO data provision and the efforts to improve the reach of EO data. By encouraging learners to find, obtain and share 
data with other learners and to comment on what they have learned and what has surprised them, they are more likely to understand why it is not enough to simply provide high quality data, in a stable format and on an easily accessible platform. This practical, interactive, peer learning aspect of the MOOC experience deepens their familiarity with the data and the need to provide tools to visualize, manipulate and communicate about the data for use by wider audiences. It also introduces them to the different ways in which different scientific communities engage with the data (e.g. in meteorology vs. oceanography), and the need for interdisciplinary approaches. In turn, observing how the learners engage with these challenges can provide further insights to inform the development of new interdisciplinary teaching and training.

\section{Case Study: How the World Bank Group's Open Learning Campus is Partnering with Earth Observation Satellite Data to Enrich the Learning Experience}

The World Bank Group is a key actor in addressing complex development challenges such as sustainable development, climate change and environmental problems. In this role the organization facilitates training, education and outreach. So too do Earth observation capacity building programs, wherein learners work to understand how sharing and visualizing geospatial data can lead to problem-solving and policy planning for development solutions. The overlap of the need for more real-world learning experiences with context-specific data has led to a partnership between the WBG and Earth observation community that is helping to transform development learning.

\section{Learning as an Accelerator to Achieve Development Goals}

The WBG has invested significantly in digital and blended learning, not only relevant to the Earth observation community, but also to a much wider global development community, including policy makers, practitioners, academics, NGOs and the general public. The WBG offers overall online education through its virtual platform, the Open Learning Campus (OLC), through which staff can refresh knowledge on a continuous basis, bridge knowledge gaps jointly with clients and co-create solutions to complex development issues, such as climate change disasters and managing epidemics.

Several drivers led the WBG to invest in the OLC as a go-to destination for development learning. Principally, it is to share this global institution's vast repository of knowledge with the wider development community and thereby transform it into a "Solutions Bank". Internally, such a platform allows for continuous learning on technical, operational and leadership topics to staff, enabling them to remain cutting-edge in their respective fields while also acquiring new competencies that 
improve their overall effectiveness in the workplace. It also enables uniform career development opportunities for staff, many of whom are in geographically dispersed time zones. Externally, Bank client countries and partners are interested in learning and co-creating solutions, leveraging the repository of development knowledgeespecially tacit knowledge-available in the institution.

At the same time several hugely and positively disruptive changes are taking place in the way education and learning is delivered. With close to six billion mobile technology connections projected by 2020 and with about $50 \%$ of the world using the Internet ${ }^{1}$, the world is increasingly connected and adept at making use of that connectivity for not only entertainment and communication but also for bringing learning tools available any time and at any place. A lot of content is found online through publicly available open educational resources (OER) like Khan Academy's flipped classroom, information downloads possible from Wikipedia, or YouTube. Vast networks of peers are available to respond to queries through Facebook, Snapchat and WhatsApp. Open learning through MOOCs has created learning communities, engaging millions of active learners worldwide. Much of this digital education in developing countries is mobile first, a by-product of the fact that computer ownership is rare for much of the developing world. Digital education is growing $14 \times$ faster than traditional higher education ${ }^{2}$, suggesting the financial motivation for further change. The increased ability to leverage big data has greatly enhanced learning analytics to understand the contexts in which learning takes place, so that online learning platforms customize learning to meet the specific development needs of learners.

The OLC is converting more and more of WBG's knowledge products and flagship reports (such as the World Development Report and country and regional technical reports) into easily accessible learning products. It is also unlocking tacit knowledge available with many of its staff, clients and partners and packaging this information into absorbable content. Rapid advances in pedagogy and technology have made these innovations possible.

\section{Progress of the OLC so Far}

The WBG has historically had a culture of face-to-face learning that is expensive and limited to small numbers of participants. It wanted to move learning away from being an "event" to becoming deeply embedded in its work. As the WBG was shifting to become more knowledge-enabled, it explored how best to deliver knowledge in the form of learning at scale and at significantly lower unit cost. The first foray into e-learning was the establishment of the e-Institute in 2011, which delivered a proof of concept for what later became the OLC. The e-Institute allowed WBG to test client and staff responsiveness and to demonstrate e-learning as a viable

\footnotetext{
${ }^{1}$ http://www.itu.int/en/ITU-D/Statistics/Pages/stat/default.aspx.

${ }^{2}$ https://www.knewton.com/infographics/the-state-of-digital-education-infographic/.
} 
tool to enhance the knowledge and skills of development practitioners who were geographically dispersed.

Encouraged by the results of the e-Institute, WBG launched the OLC in January 2016 with the objective of becoming the preferred destination for development learning. Since the launch, more than two million learners from 190 countries have visited the OLC, and approximately 6000 digital learning activities have been designed and curated, gradually starting to realize the vision of the OLC. In the years to come, the OLC will continue to convene, connect, contextualize and cocreate learning for and with our clients and development partners, making the OLC not just a destination for just-in-time content but perhaps even more importantly, a destination for problem-solving conversations and communities.

\section{Flexible Pathways to Learning}

The OLC virtual platform leverages advances in pedagogy and technology to provide distinctive formats to match the evolving needs of learners through structured courses, bite-sized lessons and vibrant communities of practice. The OLC harnesses educational technology, mobile capabilities, cloud-computing and innovations in elearning to produce a world-class learning ecosystem through three "schools" of learning, with robust content, exciting delivery methods and access from anywhere.

The first school, WB Talks, enables the learner to explore nuggets of knowledge through talks, podcasts, videos and games. These bite-sized learning opportunities are equally useful for the busy professional and the inquisitive researcher or student.

- Gender and Agriculture (2015)

- Cooperation on the Nile-Bringing Down the Glass Wall (2016)

- Towards Green Growth: Learning from Republic of Korea's Experience (2016)

- Promoting Green Competitiveness (2015)

The second school, WB Academy, helps the learner to unpack deep learning related to development challenges and solutions through virtually facilitated or selfdirected e-courses, MOOCs and materials from face-to-face courses.

- An Introduction to Land Market Assessment in Complex Urban Settings (2016)

- Designing MRV Systems for Entity-Level Greenhouse Gas Emissions (2016)

- Coffee Price Risk Management (2016)

- Water Footprint-Concept and Application (2016)

The third school, WB Connect, enables learners to engage with others through peer and expert learning to find crowd-sourced solutions to development challenges. Using a range of tools, from social media to mobile texts, knowledge exchange can be promoted between WBG staff, clients, partners and global citizens. Examples 
of such communities include urban floods, Smart Cities and integrated water management and land and house thematic groups.

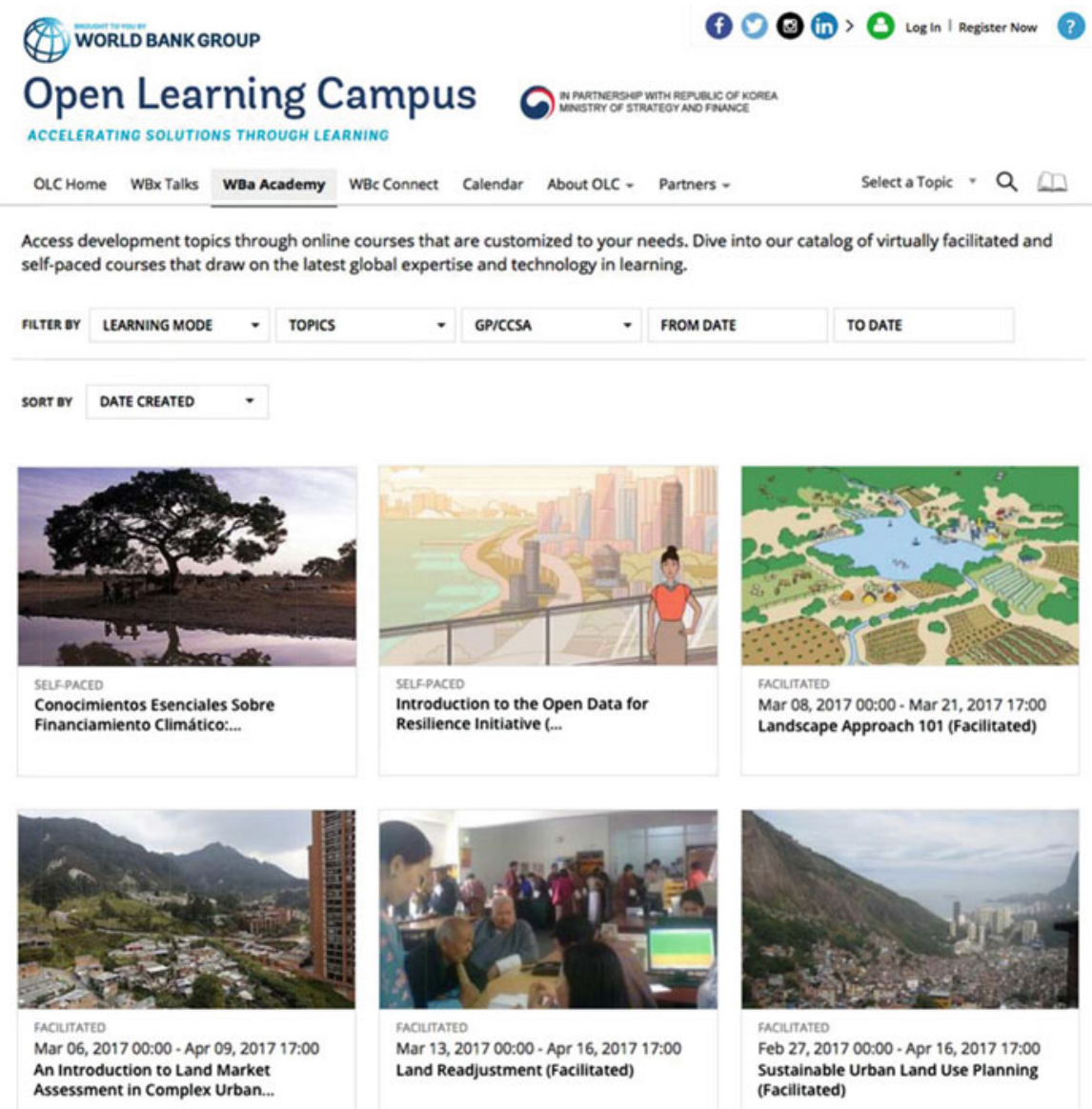

The OLC provides a rich library of learning courses and content across all sectors and regions that is curated from operational groups within the WBG and includes external global knowledge. The learning focuses on best practices and lessons from failures and is facilitated by global and regional experts on development topics from the WBG and the broader development community. The OLC also facilitates opportunities to learn from other client experiences (described as "South-South").

\section{Increasing Importance of Geospatial Data}

Various layers of geospatial data, ranging from continuous feeds from Earth observation satellites to geo-coded information on specific locations made available through sensors, are now retrievable and used for development policy and planning 
applications. Adding a geographic or spatial dimension gives the development learner greater authenticity in terms of the learning experience, while data visualization enables learners to experience realistic simulations by contextualizing information.

For example, learners are able to track air pollution in congested road arteries by the time of the day, send feedback through their mobile phones, and join discussions with traffic planning experts on the best ways to mitigate congestion and air pollution in the streets they travel in. Public participation in planning new facilities in a city, such as a park or shopping mall, could benefit from citizens who are able to visualize spatial outcomes of different proposals under consideration.

\section{Examples of How the OLC is Incorporating Spatial Data}

MOOCs are powerful vehicles to distil and share knowledge among various stakeholders, ranging from policy makers to the general public. The OLC offers the MOOC, From Climate Science to Action, thrice in English, twice in Spanish and now under finalization in French. The course guides learners through the latest research that forms the basis for predictions around the effects of climate change on their lives. It explores the projected effects of climate change across sectors, with in-depth analysis of each world region through a series of region-specific modules. Understanding how levels of carbon emissions today will affect the world tomorrow galvanizes public support for political action.

Themes from two European Space Agency (ESA) MOOCs have been incorporated into the WBG climate change MOOC. Videos from the ESA MOOC, "Monitoring Climate Change from Space," have been used to explain Earth observation concepts, how climate data from satellites are valuable inputs in policy formulation and the importance of Earth observation megatrends in wind patterns, ocean currents, etc. for policy applications and promoting global dialogues. Videos from the ESA MOOC, "Earth Observation: The Optical View," have been used to help learn about causality processes in climate change and appreciate the impacts in terms of changes in land use, forest cover, etc.

A second vehicle the OLC offers is facilitated e-learning courses. A series of facilitated e-learning courses in disaster risk management have considerable inputs from Earth observation satellites. An introductory course familiarizes learners with contemporary concepts and practices in disaster management and explains how planning approaches have moved from reactive to pro-active modes. Another course on safe and resilient cities provides urban planners with tools on vulnerability assessments, policies and programs, stock-taking and gaps analysis and financial access. The discussion also focuses on decision-making in uncertainty to identify options and establish priorities, making the city more resilient to climate change impacts and natural disasters. The seven modules of the "Sustainable Urban Land Use Planning" course give the learner a thorough grounding in best practices in urban land use planning and how to sequence regulations and investments to mitigate disaster risks. 
A third vehicle is bite-sized learning modules that provide just-in-time learning that complements the above two categories in bringing about meaningful change across all levels - from grassroots action to national policy making to international cooperation. A good example is the Spatial Agent Tutorial, which teaches how to curate data from hundreds of data sets to create on-demand visualization on wideranging topics of interest to the Earth observation satellite community, ranging from transport and trade to watersheds and climate change. Bite-sized learning on "Bits and Bricks" focuses on cities undergoing profound transformations, and on how the convergence of digital information (bits) and physical environment (bricks) are facilitated through the Internet to develop new solutions. In support of this initiative, the OLC has prepared a series of bite-sized learning videos that benefited from the Bits and Bricks conference organized by the WBG, with MIT and World Economic Forum.

\section{Issues Relevant to This Experience for the Earth Observation Community}

Key issues and messages gathered from deploying training and education in the OLC so far include:

- Transformation in learning: Learning is an important accelerator to eradicate poverty and boost shared prosperity whenever global knowledge is converted into practical actions through evidence-based and iterative learning. The OLC transforms how its target audiences learn. It integrates innovations in technology and instructional design to provide accessible, quality learning in a resource-efficient way. Emerging immersive learning modalities facilitate this transformation, by accelerating learning adoption and application. Examples include serious games, geospatial data, artificial intelligence and mobile- and cloud-based learning.

- Role of Earth observation data: The OLC provides a unique opportunity for the Earth observation community to disseminate their professional insights to the wider development community for cross-sectoral, "anytime and anywhere" learning. Spatial and Earth observation data are becoming increasingly important in several areas of WBG engagement, notably related to climate change, infrastructure service planning and delivery and citizen engagement because the costs of installing sensors are falling dramatically.

- Digital changes and connectivity: Global connectivity is increasing, leading to a "Facebook nation" of more globalized, coordinated, economic, social and political actions across borders. As WBG and its partners tackle complex challenges, many staff members and officials need to learn new skills to leverage the massive expansion in data available — not only from Earth observation satellites but also from mobile call records and sensors on the ground and under water. This data will be valuable only when it can be applied to policy formulation and project design.

- Wider dissemination: Partnerships are emerging with regional and national institutions and donors (such as the Korea Development Institute, Monterrey Tec, 
Chinese Academy of Governance, Indian National Institute of Urban Affairs) to localize courses and scale up in-country. The know-how can be disseminated globally, with the OLC playing a facilitator role.

- Citizen engagement: Influential NGO networks are also participating and contributing to the OLC, so that citizens have the opportunity to acquire the necessary knowledge and skills, and burgeoning citizen movements are persuaded to support the right kind of reforms.

\section{Case Study Conclusion}

The OLC represents the WBG commitment to harnessing the global revolution in learning to lift people out of poverty and to boost shared prosperity. Adding the geographic or spatial dimension to the OLC's learning offerings is invaluable because it provides greater authenticity to the learning experience, through big data analytics with data visualization. These types of data enable learners to undertake realistic simulations of complex policy choices and will contribute to more effective decision-making.

\section{References}

An Introduction to Land Market Assessment in Complex Urban Settings (2016) https:// olc.worldbank.org/content/introduction-land-market-assessment-complex-urban-settingsfacilitated

Atkins DE, Brown JS, Hammond AL (2007) A review of the open educational resources (OER) movement: achievements, challenges, and new opportunities

Brown JS, Adler RP (2012) Minds on fire: open education, the long tail, and learning 2.0

Coffee Price Risk Management (2016) https://olc.worldbank.org/content/coffee-price-riskmanagement-self-paced

Cooperation on the Nile-Bringing Down the Glass Wall (2016) https://olc.worldbank.org/content/ cooperation-nile-bringing-down-glass-wall

Designing MRV Systems for Entity-Level Greenhouse Gas Emissions (2016) https:// olc.worldbank.org/content/designing-mrv-systems-entity-level-greenhouse-gas-emissionsself-paced

Diaz V, Brown M, Pelletier S (2013) Learning and the massive open online course. A report on the ELI focus session. EDUCSAUSE review

Dolan P, Leat D, Mazzoli Smith L, Mitra S, Todd L, Wall K (2013) Self-organised learning environments (SOLEs) in an English school: an example of transformative pedagogy? Online Educ Res J

Elmore RF (2015a) School reform from the inside out - policy, practice, and performance. Harvard Education Press, Cambridge, MA

Elmore RF (2015b) The future is learning, but what about schooling. Inside Higher Ed

ESA Monitoring Climate from Space MOOC (2015) Imperative Space/ESA. https:// www.futurelearn.com/courses/climate-from-space

"Fabspace 2.0" project (2016) https://www.fabspace.eu/

Facer K (2007) Principles for consideration in the design of future learning environments. Futurelab 
Faulkes Telescope Project (2008) http://www.faulkes-telescope.com

FutureLearn (2015) Monitoring climate from space - course report

Gender and Agriculture (2015) https://olc.worldbank.org/content/gender-and-agriculture

Kapur R, Nieman A et al (2007) Project Faraday - exemplar designs for science. Department for Children Schools and Families, UK Government, London

Liyanagunawardena TR, Parslow P, Williams SA (2014) Dropout - MOOC participants' perspective

LUCID Project/Langton Star Centre (2014) http://www.thelangtonstarcentre.org/lucid/

Mehaffy GLM (2012) Challenge and change. EDUCSAUSE review

Mitchell J, Stevens M, Thille C (2015) What we've learned from MOOCs, Insider Higher Ed/Lytics Lab, Stanford University, Stanford, CA

National Schools Observatory Project (n.d.) http://www.schoolsobservatory.org.uk

Promoting Green Competitiveness (2015) https://olc.worldbank.org/content/lightning-talkpromoting-green-competitiveness

Research at Sheffield (2010) GovEd Communications/EPSRC/University of Sheffield. http:// www.researchatsheffield.co.uk

Smith MS, Casserly CM (2006) The promise of open educational resources. Change 38(5):8

Towards Green Growth: Learning from Republic of Korea's Experience (2016) https:// olc.worldbank.org/content/towards-green-growth-learning-republic-korea\%E2\%80\%99sexperience

Water Footprint-Concept and Application (2016) https://olc.worldbank.org/content/waterfootprint-concept-and-application-self-paced

Open Access This chapter is licensed under the terms of the Creative Commons Attribution 4.0 International License (http://creativecommons.org/licenses/by/4.0/), which permits use, sharing, adaptation, distribution and reproduction in any medium or format, as long as you give appropriate credit to the original author(s) and the source, provide a link to the Creative Commons license and indicate if changes were made.

The images or other third party material in this chapter are included in the chapter's Creative Commons license, unless indicated otherwise in a credit line to the material. If material is not included in the chapter's Creative Commons license and your intended use is not permitted by statutory regulation or exceeds the permitted use, you will need to obtain permission directly from the copyright holder. 